\title{
An audit of five years' experience of pregnancy in spinal cord damaged women. A regional unit's experience and a review of the literature
}

\author{
P A Feyi-Waboso MBBS, MRCOG \\ Women's Specialist Hospital, PO Box 53, Aba-Abia State, Nigeria.
}

In a retrospective review of pregnancy and delivery in 8 spinal cord damaged women managed at Hexham General Hospital Spinal and Maternity Units between 1986 and 1991, antenatal complications included urinary tract infection, anaemia, constipation, suspected deep venous thrombosis and pressure sores. Five of the 8 patients had adductor spasms. Autonomic hyperreflexia occurred in 2 patients in the antenatal period, and in one patient in the postpartum period. Four patients were delivered by caesarian section, and 4 of the 8 patients had breech presentation of the foetus at delivery. The perinatal outcome was good.

Key words: pregnancy; spinal cord damaged; adductor spasms; autonomic hyperreflexia; caesarean section.

\section{Introduction}

Spinal cord damage can severely handicap otherwise healthy young women. Despite their handicap they may desire to have a normal as possible life, and aspire to have their own family and family life. They pose unique management problems throughout their pregnancies, in labour and in the postnatal period.

Obstetricians, orthopaedic surgeons, neurosurgeons and general practitioners may all be involved in the care of such patients. They should therefore be aware of the potential problems that may arise. In particular, general practitioners, because of the distance to regional units, could be involved in answering questions that would normally be posed by patients to specialists. General practitioners must be aware of potential problems in order that they can meet the additional demands that may be placed upon them.

\section{Patients and methods}

Hexham General Hospital is a district general hospital serving the Tynedale district of Northumberland. The obstetric unit comprises 22 beds and undertakes approximately 800 deliveries per annum. The regional spinal unit for the Northern region, which has 33 beds for a catchment population of 3 million, is also based within the hospital.

Whenever possible women who are patients of the spinal unit and become pregnant are booked for confinement at the Hexham General Hospital. A review of labour ward delivery records from January 1986 to June 1991 identified the patients of the spinal injury unit who were delivered in the maternity unit. The case records of these women were reviewed.

\section{Results}

In the $5 \frac{1}{2}$ years studied, 8 patients at the spinal unit were booked for confinement within the maternity unit at Hexham General Hospital. Details of their age, parity, handicap and cause of handicap are given in Table I.

A number of complications were seen in the antenatal period. Urinary tract infection occurred in 6 of the 8 patients, and was treated on the basis of urine culture results. Prophylactic antibiotics were not used. Indwelling urethral catheters were used by 4 patients. All were complicated by recurrent catheter blockage and urinary tract infection. One patient employed intermittent self catheterisation. She suffered from bladder 
Table I Clinical characteristics of 8 pregnancies in 8 spinal cord damaged women: spinal details

\begin{tabular}{|c|c|c|c|c|}
\hline Case No & Age & Parity & $\begin{array}{l}\text { Neurological } \\
\text { lesion (level } \\
\& \text { cause) }\end{array}$ & Handicap \\
\hline 1 & 30 & $2^{+0}$ & $\begin{array}{l}\text { T9 } \\
\text { Transverse } \\
\text { Myelitis }\end{array}$ & Complete motor and sensory loss \\
\hline 2 & 23 & $0^{+1}$ & $\begin{array}{l}\text { C5 } \\
\text { RTA }\end{array}$ & $\begin{array}{l}\text { Complete tetraplegia (complete motor } \\
\text { and sensory loss) }\end{array}$ \\
\hline 3 & 31 & $2^{+1}$ & $\begin{array}{l}\text { T4 } \\
\text { RTA }\end{array}$ & Complete motor and sensory loss \\
\hline 4 & 31 & $0^{+1}$ & $\begin{array}{l}\text { T9 } \\
\text { Shotgun } \\
\text { Injury }\end{array}$ & Complete motor and sensory loss \\
\hline 5 & 29 & $1^{+1}$ & $\begin{array}{l}\text { T2 } \\
\text { RTA }\end{array}$ & Complete motor and sensory loss \\
\hline 6 & 26 & $1^{+1}$ & $\begin{array}{l}\text { T6 } \\
\text { RTA }\end{array}$ & $\begin{array}{l}\text { Complete motor and sensory loss } \\
\text { Flaccid paraplegia due to extensive vascu- } \\
\text { lar cord damage }\end{array}$ \\
\hline 7 & 22 & $0^{+0}$ & $\begin{array}{l}\text { T12 } \\
\text { RTA }\end{array}$ & $\begin{array}{l}\text { Complete motor loss some sensory spar- } \\
\text { ing }\end{array}$ \\
\hline 8 & 21 & $0^{+0}$ & $\begin{array}{l}\text { T6 } \\
\text { Childhood } \\
\text { Accident }\end{array}$ & Complete motor and sensory loss \\
\hline
\end{tabular}

$\mathrm{RTA}=$ Road traffic accident

instability but achieved continence by regular daily self expression of the bladder. Large bladder stones were passed spontaneously by one patient. In the postpartum period, 2 patients had acute pyelonephritis and were treated with antibiotics.

Rupture of the amniotic membranes was suspected in one patient. However, this had been confused with urinary incontinence.

All patients became anaemic and oral iron supplementation was prescribed when anaemia was diagnosed.

Other antenatal problems related to the relative immobility of these patients included constipation in all 8 patients. Of these 8,2 women required regular rectal enemas and manual evacuation. A tender swollen right leg was noticed in one patient at 33 weeks gestation. Deep venous thrombosis was diagnosed and treatment was given for the remainder of pregnancy and 6 weeks postpartum with subcutaneous he- parin. Two patients had severe sacral pressure sores.

In the antenatal period adductor spasms were experienced by 5 patients. These were severe in 3 cases, 2 of whom also had autonomic hyperreflexia with symptoms of dyspnoea and facial flushing in one patient, with a spinal cord lesion at level T4. The other with a lesion at level C5 had severe headaches associated with a mild elevation of blood pressure triggered off by recurrent catheter blockage or manual evacuation of the bowel. All 3 patients were admitted at 34 weeks gestation to the spinal unit. The other 2 patients who had occasional mild adductor spasms declined admission. In the postpartum period one patient with a high lesion at level T2 had autonomic hyperreflexia. She complained of a severe pounding headache and dizziness. She also had spasms of the leg muscles. Blood pressure was $160 / 100 \mathrm{~mm} \mathrm{Hg}$ and there was a brady- 
cardia. Treatment was successful with intravenous labetalol and diazepam. The mode of delivery and outcome of pregnancies are given in Table II.

The perinatal outcome was uniformly good in this series. There were no acute asphyxia problems, foetal abnormalities, stillbirths or neonatal deaths.

\section{Discussion}

Urinary tract infection is common in non pregnant spinal cord damaged women because of either stasis or continuous catheterisation. Pregnancy exacerbates their suscep- tibility to infection. ${ }^{1}$ Patients in this series were managed as in the non pregnant state. They were screened for infection regularly and treated on the basis of urine culture results as advocated by a European worker ${ }^{2}$ and in a recent British report. ${ }^{3}$ They did not receive chronic suppression therapy such as methenamine mandelate with ascorbic acid or nitrofurantoin as suggested in a previous report from America. ${ }^{4}$ Other American workers ${ }^{5}$ treated all their patients with long term urinary antiseptics such as methyl mandelic acid. This practice might have prevented the 2 postpartum cases of acute pyelonephritis in this series. Consideration

Table II Clinical characteristics of 8 pregnancies in 8 spinal cord damaged women: obstetric details

\begin{tabular}{|c|c|c|c|}
\hline Case No & Mode of delivery & $\begin{array}{l}\text { Anaesthesia/ } \\
\text { analgesia }\end{array}$ & Outcome \\
\hline 1 & $\begin{array}{l}\text { Elective } \mathrm{C} / \mathrm{S} \text { for previous } \mathrm{C} / \mathrm{S} \text { and } \\
\text { breech presentation at } 38 \text { weeks }\end{array}$ & Not required & $\begin{array}{l}\text { Female } \\
3.4 \mathrm{~kg} \\
\text { Apgar } 9 / 10\end{array}$ \\
\hline 2 & $\begin{array}{l}\text { Elective } \mathrm{C} / \mathrm{S} \text { for autonomic hyper- } \\
\text { reflexia and breech presentation at } \\
39 \text { weeks }\end{array}$ & General anaesthetic & $\begin{array}{l}\text { Male } \\
3.2 \mathrm{~kg} \\
\text { Apgar } 8 / 10\end{array}$ \\
\hline 3 & $\begin{array}{l}\text { Emergency } \mathrm{C} / \mathrm{S} \text { for autonomic hyper- } \\
\text { reflexia } \\
\text { Breech presentation preterm labour } \\
\text { at } 35 \text { weeks }\end{array}$ & General anaesthetic & $\begin{array}{l}\text { Female } \\
2.35 \mathrm{~kg} \\
\text { Apgar } 8 / 8\end{array}$ \\
\hline 4 & SVD (painless labour) at 37 weeks & not required & $\begin{array}{l}\text { Female } \\
2.2 \mathrm{~kg} \\
\text { Apgar } 9 / 10\end{array}$ \\
\hline 5 & SVD at 38 weeks & Pethidine & $\begin{array}{l}\text { Female } \\
2.8 \mathrm{~kg} \\
\text { Apgar } 9 / 10\end{array}$ \\
\hline 6 & $\begin{array}{l}\text { SVD } \\
\text { Following SROM at } 38 \text { weeks }\end{array}$ & Pethidine & $\begin{array}{l}\text { Female } \\
3.4 \mathrm{~kg} \\
\text { Apgar } 8 / 9\end{array}$ \\
\hline 7 & $\begin{array}{l}\text { IOL at } 38 \text { weeks because of severe } \\
\text { spasms of abdominal and leg muscles } \\
\text { Kiellands rotation forceps for worsening } \\
\text { adductor spasms in second stage of labour }\end{array}$ & Pudendal block & $\begin{array}{l}\text { Male } \\
2.9 \mathrm{~kg} \\
\text { Apgar } 8 / 10\end{array}$ \\
\hline 8 & $\begin{array}{l}\text { Elective } \mathrm{C} / \mathrm{S} \text { for footling breech at } \\
38 \text { weeks }\end{array}$ & Epidural & $\begin{array}{l}\text { Female } \\
3.2 \mathrm{~kg} \\
\text { Apgar } 8 / 10\end{array}$ \\
\hline
\end{tabular}

SROM = Spontaneous rupture of membranes

$\mathrm{SVD}=$ Spontaneous vertex delivery

$\mathrm{C} / \mathrm{S}=$ Caesarean section

$\mathrm{IOL}=$ Induction of labour 
should be given to prophylactic antibodies if infection persists or recurs. ${ }^{3}$

All patients became anaemic during pregnancy with a haemoglobin concentration of $<11 \mathrm{~g} / \mathrm{dl}$. They were treated with iron tablets. Although all patients had chronic constipation exacerbated by pregnancy this makes a strong case for prophylactic iron with stool softeners to prevent intestinal complications as reported from America. ${ }^{5}$

Despite meticulous physiotherapy, 2 patients had pressure sores which prolonged their immobility. Both cases were worse because of further immobilisation by advanced pregnancy. Immobility was also related to the potentially fatal complication of suspected deep venous thrombosis in one patient in the antenatal period. In view of the fact that she had been in bed because of bed sores which reduced her mobility, it was thought wise to treat this as deep venous thrombosis based on strong clinical suspicion. Venous thromboembolism is the major cause of maternal death in the United Kingdom (HMSO Publications 1985-87). ${ }^{18}$ The recommendation is that any woman with a suspected deep venous thrombosis should be given full anticoagulant therapy. The increased susceptibility of venous thrombosis in the spinal paralysed is increased even further by pregnancy. ${ }^{6}$ Certainly there should be no reluctance to use prophylactic anticoagulants.

Interestingly 4 of the 8 patients had breech presentation of the foetus at delivery. Although the numbers are too few to draw a firm conclusion, there appears to be an increased incidence in spinal cord damaged women. It was not routine to admit all patients to hospital from 34 weeks gestation, but those with autonomic hyperreflexia were advised about this and were kept in hospital until delivery. American workers ${ }^{4}$ have suggested weekly cervical examinations in the clinic beginning at 28 weeks to detect cervical effacement or dilatation and to prevent delivery outside the hospital.

This was felt to be unnecessarily invasive in this series of patients and such a stimulus may cause autonomic hyperreflexia. ${ }^{5}$ Ultrasound imaging could be used to determine cervical effacement and dilatation with probably reduced risk of autonomic hyper- reflexia and adductor spasms. Moreover those women with high lesions who had regular adductor spasms were under surveillance in hospital to avoid an unattended delivery at home. One patient with a T9 lesion who had a spontaneous painless labour at 37 weeks called a nurse as she thought her catheter was leaking. She was found to have the foetal head crowning.

Caesarean section should be reserved for obstetric indications. ${ }^{7-9}$. Nevertheless, the occurrence of autonomic hyperreflexia influenced the decision to perform caesarean section for breech presentation in 2 cases. The indications for the other 2 caesarean sections performed were purely obstetric.

The highly variable but potentially lethal syndrome of autonomic hyperreflexia occurs in up to two thirds of cord damaged labouring women whose lesions are above the T6 level. ${ }^{11}$

Autonomic hyperreflexia may occur when patients attempt intermittent self catheterisation or evacuate their bowels during pregnancy as occurred in 2 patients in this series. It may affect intrapartum management as it can be triggered off by attempts to catheterise or examine patients during labour.

Potentially serious problems may result including convulsions, permanent neurological deficits, intracerebral haemorrhage and death. $1,3,11-15$

Epidural anaesthesia is an effective method for controlling autonomic hyperreflexia during labour and delivery. It is indicated for both patient comfort and prevention of hypertension which may lead to a cardiovascular accident, ${ }^{16}$ and also for patients in labour with breech presentation. ${ }^{19}$ Two patients had general anaesthesia rather than epidural anaesthesia for their caesarean sections. In one case with a C5 cord injury, the epidural space had been infected on a previous occasion and she requested a general anaesthetic. The indication for general rather than epidural anaesthesia in the second case was the patient's request. The decision had been made to induce labour in one patient with a T6 spinal cord lesion and breech presentation at 38 weeks because of worsening adductor spasms. Epidural anaesthesia was planned. 
However, footling breech presentation was diagnosed at vaginal examination. Therefore an elective caesarean section under epidural anaesthesia was performed for this purely obstetric indication.

Symptoms of autonomic hyperreflexia are clearly related to uterine contractions ${ }^{9}$ and disappear completely at the end of the third stage of labour. ${ }^{17}$ The end of a contraction and delivery result in rapid resolution of all signs and symptoms of dysreflexia. ${ }^{3}$

One patient with a high spinal cord lesion at level T6 experienced autonomic hyperreflexia in labour. Interestingly, in a patient with a lesion at level T2 it occurred in the postpartum period, 30 minutes after completion of the third stage. It is possible that uterine contractions not perceived by the patient after completion of the third stage were the stimulus. The diagnosis of eclampsia was excluded. This finding is contrary to previous reports ${ }^{9}$ and suggests that surveil- lance for autonomic hyperreflexia in those patients at risk should continue into the immediate postpartum period and not be confined to pregnancy and labour.

\section{Conclusion}

Patients with spinal cord injury may be expected to have a reasonably normal pregnancy outcome provided that potential problems particularly related to immobility and autonomic hyperreflexia are anticipated and those involved in their care are familiar with the management of such problems.

\section{Acknowledgements}

I wish to thank $\mathrm{Mr} \mathrm{R}$ A Sutton, Consultant Orthopaedic Surgeon and Dr J Jeffery of the anaesthetic staff for their advice. Also thanks to Denise Bowers for typing the manuscript.

\section{References}

1 Abouleish E (1980) Hypertension in a paraplegic parturient. Anaesthesiology 53: 348 .

2 Berard EJJ (1989) The sexuality of spinal cord injured women: physiology and pathophysiology, a review. Paraplegia 27: 99-112.

3 Hughes SJ, Short DJ, Usherwood M, Tebbutt H (1991) Management of the pregnant woman with spinal cord injuries: Br J Obstet Gynaecol 98: 513-518.

4 Greenspoon JS, Paul RP (1986) Paraplegia and quadriplegia: special considerations during pregnancy and labour and delivery. Am J Obstet Gynecol 155: 738-741.

5 Young BKE, Katz M, Klein S (1983) Pregnancy after spinal cord injury: altered maternal and foetal response to labour. Obstet Gynecol 62: 59-63.

6 Oppenheimer WM. Pregnancy in paraplegic patients: two case reports. Am J Obstet Gynaecol 110: $784-786$

7 Goeller H, Paeslack V (1970) Our experiences about 784-786 pregnancy and delivery of the paraplegic woman. Paraplegia 8: 161-166.

8 Rossier AB, Ruffieux M, Ziegler WH (1969) Pregnancy and labour in high traumatic cord lesions. Paraplegia 7: 210-216.

9 Robertson DNS (1972) Pregnancy and labour in the paraplegic. Paraplegia 10: 207-210.

10 Verduyn WH (1984) Spinal cord injured women: pregnancy and delivery. International Medical Society of Paraplegic Denver, Colorado.

11 Frankel HL Guttmann L, Paeslack V (1965) Cardiac irregularities during labour in paraplegic women. Paraplegia 3: p 144.

12 Guttmann L (1963) The paraplegic patient in pregnancy and labour. Proc $R$ Soc Med 56: 383-387.

13 Hardy AG, Warrel DW (1965) Pregnancy and labour in complete tetraplegia. Paraplegia 3: $182-188$.

14 Kurnick NB (1956) Autonomic hyperreflexia and its control in patients with spinal cord lesions. Ann Int Med 44: 678-686.

15 McGregor JA, Meeuwsen MD (1985) Autonomic hyperreflexia: a mortal danger to spinal cord-damaged women in labour. Am J Obstet Gynecol 151: 330-333.

16 Watson DW, Downey GO (1980) Epidural anaesthesia for labour and delivery of twins of a paraplegic mother. Anaesthesiology 52 (3): 259-261.

17 Nath M, Vivian JM, Cherny WB (1979) Autonomic hyperreflexia in pregnancy and labor: a case report. Am J Obstet Gynecol 134: 390-392.

18 HMSO Publications 1985-87. Report of Confidential Enquiries into Maternal Deaths in the United Kingdom: Thrombosis and Thrombo-embolism 1985-87: 37-45.

19 Selwyn Crawford J (1985) Lumbar epidural analgesia for labour and delivery. In: Studd J, editor. The Management of Labour. Blackwell Scientific Publications Ltd, Oxford: 226-234. 